\title{
Friction Stir Welding of Al 5052 with Al 6061 Alloys
}

\author{
N. T. Kumbhar' ${ }^{1}$ and K. Bhanumurthy ${ }^{2}$ \\ ${ }^{1}$ Materials Science Division, Bhabha Atomic Research Centre, Trombay, Mumbai 400 085, India \\ ${ }^{2}$ Scientific Information Resource Division, Bhabha Atomic Research Centre, Trombay, Mumbai 400 085, India
}

Correspondence should be addressed to K. Bhanumurthy, aditya@barc.gov.in

Received 29 November 2011; Accepted 19 February 2012

Academic Editor: Stan A. David

Copyright ( 2012 N. T. Kumbhar and K. Bhanumurthy. This is an open access article distributed under the Creative Commons Attribution License, which permits unrestricted use, distribution, and reproduction in any medium, provided the original work is properly cited.

Friction stir welding (FSW), a solid-state joining technique, is being extensively used in similar as well as dissimilar joining of Al, $\mathrm{Mg}, \mathrm{Cu}, \mathrm{Ti}$, and their alloys. In the present study, friction stir welding of two aluminium alloys-AA6061 and AA5052—was carried out at various combinations of tool rotation speeds and tool traverse speeds. The transverse cross-section of the weld was used for optical as well as electron microscopy observations. The microstructural studies were used to get an indication of the extent of material mixing both at the macro- and microscales. It was observed that, at the interface region, both materials exhibited similar texture despite the nonrigorous mixing of the materials in the nugget. The extent of interdiffusion of alloying elements at the interface was studied using electron probe microanalysis. The tensile testing evaluation of these specimens showed good mechanical properties. The interdiffusion of alloying elements and development of similar orientations in the nugget could have contributed to the better tensile properties of the friction-stir-welded AA5052-AA6061 specimens.

\section{Introduction}

The joining of dissimilar materials is vital, since it is intended to obtain a product having a combination of desirable properties of both parent materials. The difficulties in joining materials with vastly differing properties using conventional fusion welding methods are well known. The selection of an appropriate filler material (having intermediate properties) is critical. Otherwise, the possible formation of complex, brittle, intermetallic compounds can degrade the quality of the weld, resulting in inferior welds. Similarly, it is not straight forward to directly join these materials using solid-state joining methods-given the compatibility issues of physical properties of the materials as well as formation of intermetallic compounds. Hence suitable interlayer which prevents the formation of intermetallic compounds is often employed in such cases.

Friction stir welding (FSW) has become an obvious choice for welding of "difficult to weld" aluminium alloys ( $5 \mathrm{xxx}$ series) or high-strength aluminium alloys (2xxx and $7 \mathrm{xxx}$ series). It has also facilitated welding of dissimilar aluminium alloys with same ease. The dissimilar welding of aluminium alloys has attracted more attention, since it offers an insight into many phenomena (e.g., material flow) which were not clear during the friction stir welding of similar $\mathrm{Al}$ alloys. Many topics like variation of microhardness, material flow, material location, temperature distribution, residual stresses, and so forth, across the interface of the abutting materials and their consequent effect on the mechanical properties are of interest to many researchers [1-3].

Lee et al. [1] studied the dissimilar lap joint FSW of AA5052-H112 and AA6061-T6 plates having thickness of $1 \mathrm{~mm}$ and $2 \mathrm{~mm}$, respectively, with various tool rotation speeds and tool traverse speeds according to the fixed location of each material on top or bottom sheet. They found that the interface morphologies were characterized by interface pull-up and pull-down in the advancing side and retreating side. The thickness of the thinner AA5052 sheet lessened due to the vertical movement of the materials. It was identified that the amount of vertical transport increased and consequently the thickness of AA5052 decreased when the heat input was increased either by increasing the tool rotation speeds or by decreasing the tool traverse speeds. Joint strengths mainly depended on the interface morphology and vertical movement of material. 
TABLE 1: Chemical composition of alloying elements in the aluminium alloys (in wt.\%).

\begin{tabular}{ccccccccccccc}
\hline & $\mathrm{Mg}$ & $\mathrm{Si}$ & $\mathrm{Mn}$ & $\mathrm{Cr}$ & $\mathrm{Ni}$ & $\mathrm{Fe}$ & $\mathrm{Ca}$ & $\mathrm{Cu}$ & $\mathrm{Zn}$ & $\mathrm{Ti}$ & $\mathrm{Al}$ \\
\hline AA5052 & 2.30 & 0.15 & 0.02 & 0.10 & - & 0.20 & - & 0.02 & 0.01 & 0.01 & $\mathrm{Bal}$ \\
AA6061 & 0.92 & 0.60 & 0.06 & - & 0.18 & 0.33 & 0.2 & - & 0.03 & 0.02 & $\mathrm{Bal}$ \\
\hline
\end{tabular}

TABLE 2: Mechanical properties of aluminium alloys AA5052 and AA6061.

\begin{tabular}{lcccc}
\hline Material & $\begin{array}{c}\text { UTS } \\
(\mathrm{MPa})\end{array}$ & $\begin{array}{c}\text { YS } \\
(\mathrm{MPa})\end{array}$ & $\begin{array}{c}\text { Elongation } \\
(\%)\end{array}$ & $\begin{array}{c}\text { Hardness } \\
(\mathrm{VHN})\end{array}$ \\
\hline AA5052 & 262 & 214 & 10 & 80 \\
AA6061 & 310 & 276 & 12 & 107 \\
\hline
\end{tabular}

Park and Kim [2] investigated the effect of tool rotation speed and tool traverse speed on the stirring action and friction heat during FSW experiments on dissimilar Al alloysAA5052-O and AA6061-T6. They used a range of process parameters to determine the mechanical strength of weld nugget of the dissimilar materials. They concluded that the optimum conditions were a traveling speed of $61 \mathrm{~mm} / \mathrm{min}$ and rotation speed of $1600 \mathrm{rpm}$. Their observations of the weld surface finish and plastic flow behaviour showed that the stirring effect increased and number of defects decreased when the traverse speed was decreased.

Park et al. [3] investigated the effect of material locations on the properties of dissimilar FSW joints of AA5052-H32 and AA6061-T6. They showed that the material mixing patterns in FSW joints vary depending on the location of base materials. For the given aluminium alloys, the materials were more properly mixed when AA5052-H32 was in the advancing side and AA6061-T6 was in the retreating side than the case of AA6061-T6 in the advancing side and AA5052-H32 aluminium alloy in the retreating side. It was found that for both combinations of material arrangement, AA5052-H32 showed the lowest value of microhardness in the heat-affected zone (HAZ), which clearly explained the reasons for the fracture of tensile test specimens at the 5052-H32 side.

The present study describes the microstructural development and resulting mechanical properties associated with the dissimilar friction stir welding of Al alloys-AA5052 and AA6061.

\section{Experimental}

In the present friction stir welding studies, two commercial aluminium alloys AA5052 and AA6061 were used-former being a partially recrystallized solid solution-strengthened aluminium alloy and latter being a precipitate-hardened aluminium alloy. The AA6061 was in the solutionized condition (solution heat treated at $530^{\circ} \mathrm{C}$ for duration of $0.5 \mathrm{~h}$, followed by water quenching), whereas the AA5052 was in the as-received state. The chemical composition and mechanical properties of these alloys are listed in Tables 1 and 2, respectively.

The FSW experiments were carried out using a dedicated, locally designed and fabricated friction stir welding equipment at the Mechanical Engineering. Deptment, Indian Institute of Science, Bangalore. During the experiments, a data logger was used to collect the data (consisting of normal load, traverse load, spindle torque, etc.) from load cells attached to the equipment. The dimensions of the workpieces used were $300 \mathrm{~mm} \times 50 \mathrm{~mm} \times 5 \mathrm{~mm}$. Prior to welding, one side of the workpieces was machined in the transverse long section plane (length-thickness plane) using a milling equipment. This facilitated a good contact of the mating surfaces with each other when arranged in a butt configuration. The workpieces were cleaned thoroughly by acetone to remove any dirt, organic material, and fine particles left after the machining process. A commercial high speed steel (HSS) tool, having a cylindrical geometry with $4.8 \mathrm{~mm}$ pin length and $6 \mathrm{~mm}$ pin diameter and having $25 \mathrm{~mm}$ shoulder diameter was used. The tool tilt was kept constant at $3^{\circ}$ for all welding trials. Several FSW trials were carried out at 1120 and $1400 \mathrm{rpm}$ and for various traverse speeds ranging from $60 \mathrm{~mm} / \mathrm{min}, 80 \mathrm{~mm} / \mathrm{min}$ and $100 \mathrm{~mm} / \mathrm{min}$. Depending on the combination of tool rotation speed and tool traverse speed used, the specimens were assigned identities according to the nomenclature ( $\mathrm{R}$ "tool rotation speed" $F$ "tool traverse speed" where R"tool rotation speed" refers to the tool rotation speed in rpm and F"tool traverse speed" refers to the feed or the tool travel rate in $\mathrm{mm} / \mathrm{min}$; e.g., the process parameter combination of $1120 \mathrm{rpm}$ and $100 \mathrm{~mm} / \mathrm{min}$ is designated as R1120F100). The qualification of defect-free joints was done using X-ray radiography and dye penetration tests. It was observed that for R1400F080 specimen (welded at tool rotation speed of $1400 \mathrm{rpm}$ and tool traverse speed of $80 \mathrm{~mm} / \mathrm{min}$ ) defect-free joints were obtained all along the interface.

The transverse cross-section of the weld was used for optical as well as electron microscopy observations. This transverse section was carefully prepared using standard metallographic techniques to obtain a mirror-like surface finish. For optical microscopy, the polished specimens were chemically etched with an etchant to reveal the microstructure. The etchant used was a diluted solution of $5 \mathrm{~mL} \mathrm{HF}+$ $10 \mathrm{~mL} \mathrm{H}_{2} \mathrm{SO}_{4}$ in $85 \mathrm{~mL}$ water. A microhardness profile was obtained in the midthickness region across this structure using a load of $50 \mathrm{~g}$ and a $10 \mathrm{~s}$ dwell time. A Cameca SX100 electron probe microanalyzer (EPMA) equipped with three wavelength dispersive spectrometers was used at an operating voltage of $20 \mathrm{kV}$ and regulated beam current of $20 \mathrm{nA}$ for determining the chemical composition. For electron backscattered diffraction (EBSD), the specimens were electropolished at $-40^{\circ} \mathrm{C}$ and $11 \mathrm{~V}$ in a solution containing $20 \mathrm{vol}$ pct perchloric acid and $80 \mathrm{vol}$ pct ethyl alcohol. The EBSD measurements were obtained on a Fei quanta-200 HV SEM with TSL-OIM package. The details of the conventions 


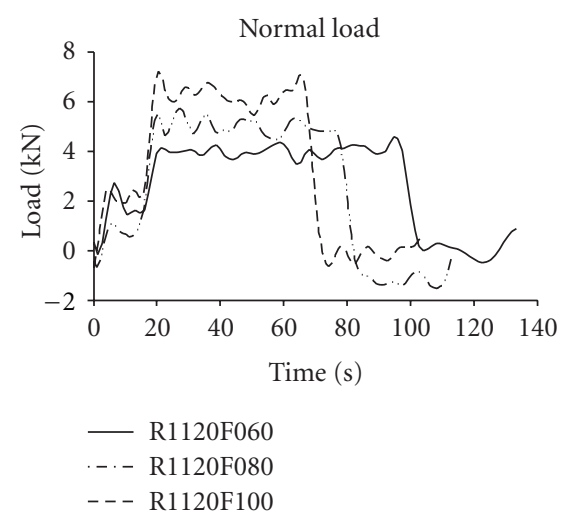

(a)

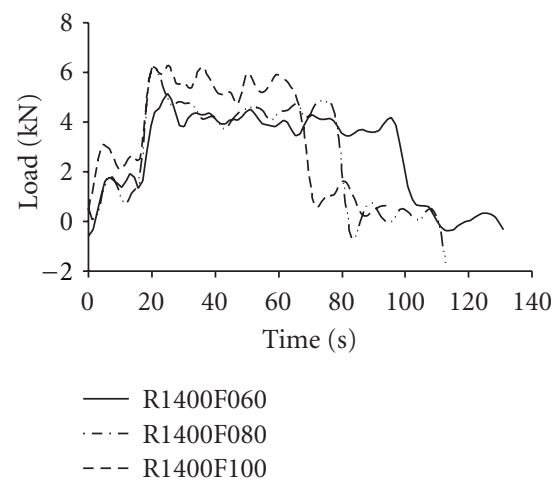

(d)
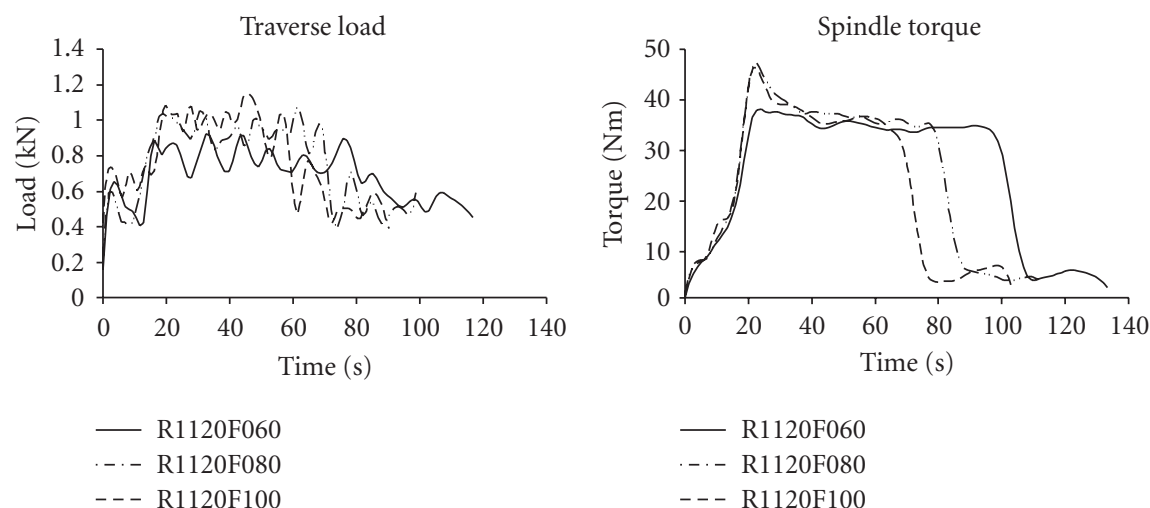

- R1120F060

-..- R1120F080

- - R $1120 \mathrm{~F} 100$

(b)

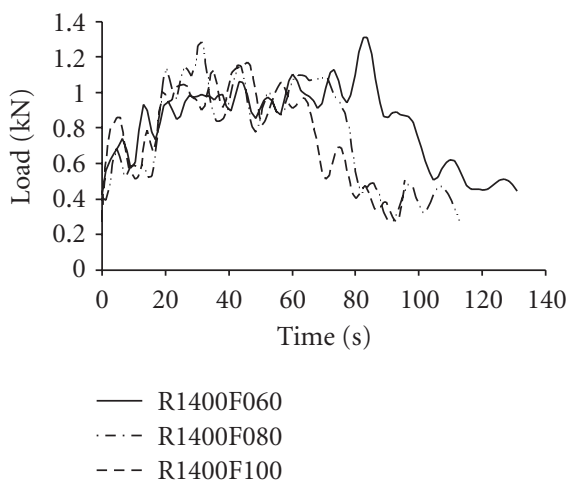

(e) (c)

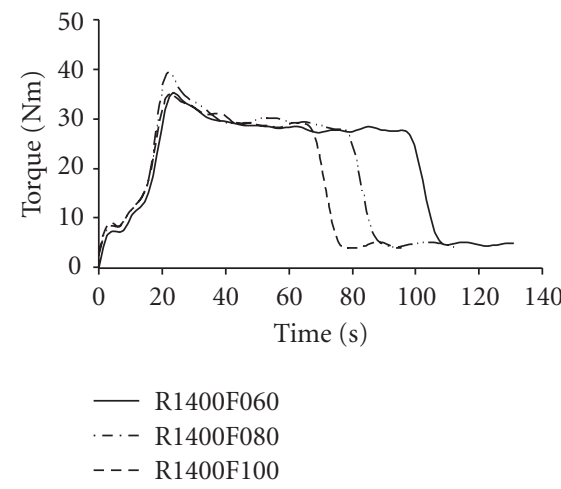

(f)

FIGURE 1: Variation of normal load, traverse load, and spindle torque with respect to time during friction stir welding of AA6061 and AA5052 experiments at various combinations of process parameters.

adopted for EBSD data analysis and various forms of representation/analysis of microtexture data are described in another work published by the authors [4].

Standard tensile specimen having gauge length of $25 \mathrm{~mm}$ and gauge width of $5 \mathrm{~mm}$ was cut using electrodischarge machine (EDM) from the welded plates by keeping the tensile axis perpendicular to the welding direction. The gauge length of the tensile specimen extended from the stir zone into the parent material. The tensile specimens were tested by using screw-driven Instron machine at a strain rate of $10^{-4} \mathrm{~s}^{-1}$.

\section{Results and Discussion}

3.1. Process Parameters Optimization. The variation of normal load, traverse load, and spindle torque with respect to time during the experimental trials for FSW of AA5052AA6061 is shown in Figure 1. A detailed description of the dynamics of variation of load (both normal and traverse) and torque during the FSW of AA5052 is given in Section 4.1 of Chapter 4 of [5]. From the friction stir welding experiments for dissimilar combination of AA5052 and AA6061, it was noticed that the normal load experienced by the tool varied in the range $3.5-7 \mathrm{kN}$ at rotation speed of $1120 \mathrm{rpm}$. Whereas at a higher rotation speed of $1400 \mathrm{rpm}$, the normal load was found to decrease and was in the range $3.5-6 \mathrm{kN}$. It was found that during FSW AA5052-AA6061 trials, the normal load was less at higher rotation speed of $1400 \mathrm{rpm}$. However no conclusive statement can be made for the normal load at rotation speed of $1120 \mathrm{rpm}$. The traverse load was in the range $0.6-1.2 \mathrm{kN}$ and $0.7-1.3 \mathrm{kN}$ for rotation speeds of 1120 and $1400 \mathrm{rpm}$, respectively. The spindle torque decreases with an increase in the rotation speed. Spindle torque values in the traversing phase were in the range of $33-38 \mathrm{Nm}$ at $1120 \mathrm{rpm}$ and $25-30 \mathrm{Nm}$ at $1400 \mathrm{rpm}$. Further, it was observed that for a particular rotation speed, the spindle torque was not affected with the variation in traverse speeds $(60,80$, and $100 \mathrm{~mm} / \mathrm{min}$ ).

3.2. Microstructural Characterization. Figure 2 shows a motif of the optical images of the cross-section of a FSW AA5052AA6061 R1400F080 specimen. The different regions of the dissimilar friction stir weld are marked in the figure. It can be noticed that the interface between AA5052 and AA6061, which initially was linear prior to welding, now has a nonlinear, wavy, and distorted appearance. The interface appears to be serrated throughout the thickness of the weld. This interface can be considered to be an imperfection and was termed as "joint-line remnant" by Threadgill [6]. It must be noted that the presence of joint-line remnant does not affect the tensile properties of the welds [6]. However, with the 


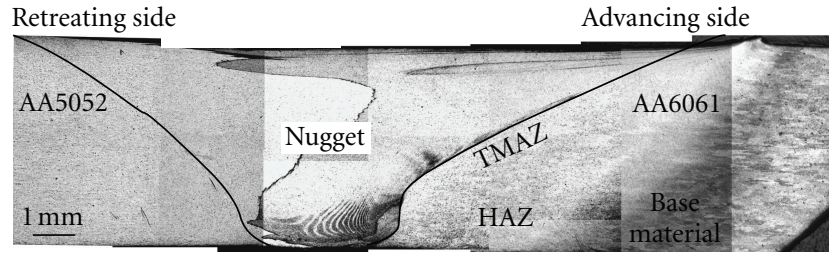

FIGURE 2: Motif of optical images of the transverse cross-section of FSW AA5052-AA6061 R1400F080 specimen showing the various regions.

present combination of process parameters (R1400F080) used, macroscopic mixing of the materials (AA5052 and AA6061) was not observed in the nugget. Several researchers $[2,7-11]$ have studied the formation of complex intercalation structures consisting of swirl-like features and intermingled dissimilar lamellae during the intermixing occurring in FSW of dissimilar materials. Park and Kim [2] have shown various micrographs to illustrate the degree of material mixing taking place for the same combination of aluminium alloys (AA5052 and AA6061) using a constant rotation speed of $1250 \mathrm{rpm}$ and various traverse speeds (ranging from $15 \mathrm{~mm} / \mathrm{min}$ to $507 \mathrm{~mm} / \mathrm{min}$ ). A primary reason for the observed effective mixing being the use of a threaded tool for the FSW trials. On the contrary, Colligan [12] pointed out that during the FSW process, not all the material influenced by the tool pin was stirred: much of the material movement was governed by extrusion.

In the present investigation, an unthreaded tool was used. Hence significant amount of intermixing among the two alloys was not seen. Lorrain et al. [10] reported that the material flow with an unthreaded tool had the same features as the material flow using threaded tools: deposition of the material at the advancing side (AS) in the upper part of the weld and at the retreating side (RS) in the lower part of the weld. In the present case, the mixing of the materials was not as effective as observed by Park et al. [3]. Park et al. [3] observed that the mixing of the materials was more effective when the AA5052 was on the advancing side for the AA5052-AA6061 FSW combination. In the present study, after etching, a swirl zone could be noticed at the bottom of the nugget zone confined to the AA6061 regime. This was in agreement with the results of Ouyang and Kovacevic [7], who reported vortex-like features for FSW AA6061. The advancing side interface at the AA6061 side was clearly seen, but the retreating side interface at the AA5052 side was difficult to demarcate.

In Figure 2 a distinct HAZ can be recognized on the AA6061-side, whereas no such characteristic region is distinguishable on the AA5052 at the retreating side. AA5052 being a solid solution-strengthened alloy, no effect of heat could be observed on it near the HAZ. AA6061 is a precipitationhardened alloy and the effect of the heat during the deformation process was clearly reflected in the microstructure, in the form of HAZ which appeared brighter than the adjoining nugget and base material (BM).

Figure 3(a) shows the low magnification optical micrograph of the R1400F080 specimen. A secondary electron image of a region in the nugget denoted by the rectangle " $\mathrm{X}$ " is shown in Figure 3(b). Line AB in the midthickness region shows the location of microhardness profile across the crosssection of friction stir welded AA5052-AA6061 R1400F080 specimen. Similarly line PQ in Figure 3(b) shows the location of the line profile analysis for $\mathrm{Al} \mathrm{K} \alpha, \mathrm{Mg} \mathrm{K} \alpha$ and $\mathrm{Si} \mathrm{K} \alpha$, across the AA5052-AA6061 interface shown in Figure 3(c). It was noticed that the width of interdiffusion was approximately $80 \mu \mathrm{m}$, for a relatively small duration of annealing (approx a few minutes). In this figure the occasional spikes in the Si K $\alpha$ curve indicate the presence of Si-rich second-phase particles. Thus it was concluded that despite the insufficient intermixing of materials (AA5052 and AA6061) caused by the stirring action of the tool, it did not result in a simple mechanical interlocking of the aluminium alloys. It is observed from the EPMA profiles in Figure 3(c) that there is substantial interdiffusion of the alloying elements.

Figure 4(a) shows the inverse pole figure map of a region at the interface of AA5052 and AA6061 in the nugget of FSW AA5052-AA6061 R1400F080 specimen. The region shows refined grains in the nugget for both the aluminium alloys. This region shown was partitioned into two regions $\mathrm{A}$ and B. Region A comprised of fine grains of AA6061 while region B comprised of a refined microstructure of AA5052. The average grain diameters for regions $A$ and $B$ were 11 and $20 \mu \mathrm{m}$, respectively. From the chart of the $\{111\}$ pole figures of these regions shown in Figure 4(b), it could be seen that the orientation distribution was similar for both the aluminium alloys. Most of the $\{111\}$ poles were aligned in the ND direction (i.e., parallel to the welding direction).

\subsection{Mechanical Properties Evaluation}

3.3.1. Microhardness. Figure 5 shows the variation of microhardness across the transverse cross-section of FSW AA5052AA6061 R1400F080 specimen in the midthickness region along line $\mathrm{AB}$ (shown in Figure 3(a)). In the figure, the filled and unfilled symbols denote the microhardness values corresponding to the regions/domains of AA5052 and AA6061 alloys, respectively. An abrupt transition across the AA5052AA6061 interface in the nugget was observed as one proceeds from the AA5052 towards AA6061. It must be noted that the microindentation in the nugget was performed at intervals of $250 \mu \mathrm{m}$. From the EPMA profiles shown in Figure 3(c), it was observed that the width of the transition region was approximately $80 \mu \mathrm{m}$. Hence any possible smooth change (transition) in the microhardness was not observed using the microindentation technique. The microhardness values remained nearly constant in the nugget and the adjoining HAZ for both the aluminium alloys (56-61 VHN in AA5052 and 86-91 VHN in AA6061). Beyond the HAZ into the base material region, there was a smooth transition of the microhardness to the parent material microhardness valuesdecreasing from the higher hardness in the nugget at the AA6061 side and increasing from lower hardness in the nugget at the AA5052 side.

In an earlier work [4] reported by the authors on FSW of AA5052, it was observed that there was a slight increase 


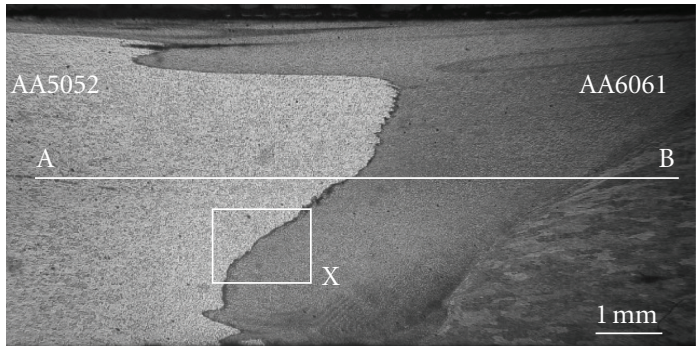

(a)

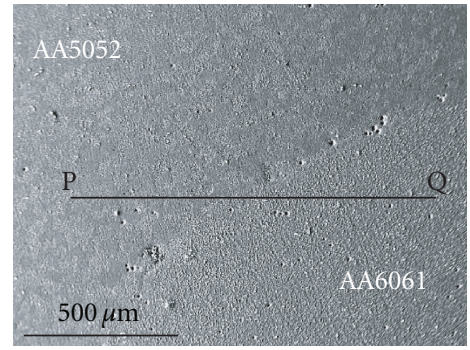

(b)

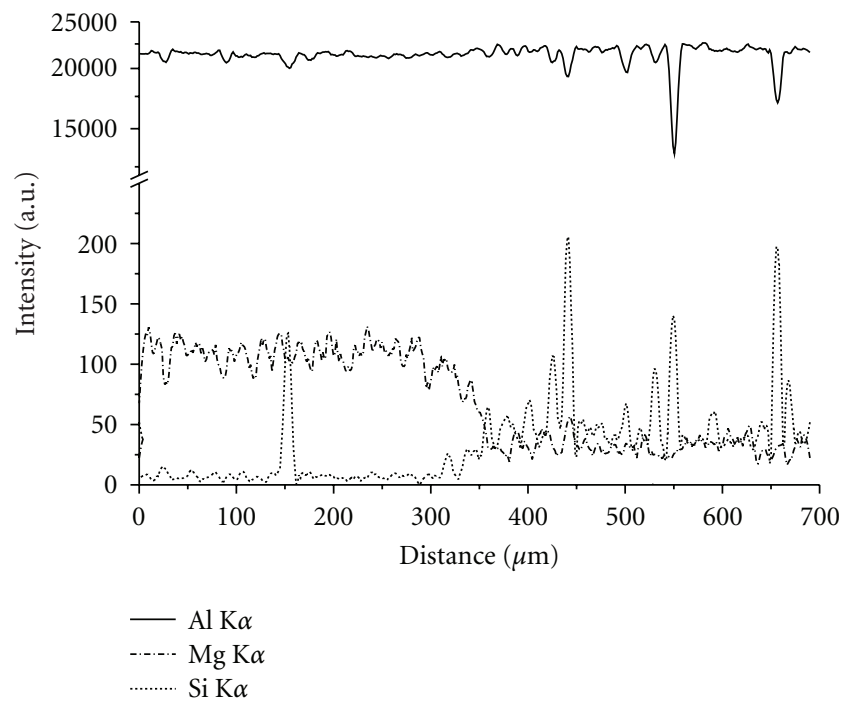

(c)

FIgURE 3: (a) Low-magnification optical micrograph of as-welded AA5052-AA6061 R1400F080 specimen. (b) Secondary electron image of region X in (a) corresponding to the interface of AA5052 and AA6061 in the nugget. (c) Intensity profiles of Al K $\alpha, \mathrm{Mg} \mathrm{K} \alpha$ and Si K $\alpha, \mathrm{X}$-ray lines along line PQ shown in (b).

in the microhardness at the nugget-TMAZ interface on the advancing side. No such distinct rise in the microhardness was noticed at the nugget-TMAZ interface on the advancing side for the present work on FSW of AA5052-AA6061.

\subsubsection{Tensile Testing. Figure 6 shows the results of the tensile} tests of FSW AA5052-AA6061 specimens. On the abscissa, the process parameters have been arranged in the decreasing order of the weld pitch (ratio of traverse speed to rotation speed expressed in $\mathrm{mm} / \mathrm{rev}$ ) implying that the heat input increases as one advances from the left to right. The process parameters on the left result in lower heat input whereas the process parameters on the right have higher heat input. It was noticed that the R1120F100 specimen with the lowest heat input resulted in inferior tensile properties compared to the other specimen. The rest of the specimen gave good indication of strength $(\sim 225 \mathrm{MPa})$ where the ultimate tensile strengths were comparable and the values of the yield strengths were in the range of 135-150 MPa. It was observed that the process parameters with high heat input resulted in good ductility $(\sim 7 \%)$. Overall, it was observed that the use of higher rotation speeds ( $1400 \mathrm{rpm}$ ) was essential to provide good heat input and the welds thus obtained had good tensile strength. The results for the tensile testing of FSW AA5052AA6061 specimen were found to be consistent with the results obtained by Park et al. [3] for the same alloy system. According to their results, for tool rotation and traverse speeds of $2000 \mathrm{rpm}$ and $100 \mathrm{~mm} / \mathrm{min}$, respectively, the ultimate tensile strength and yield strength were $\sim 220 \mathrm{MPa}$ and $110 \mathrm{MPa}$, respectively. However, the \% elongation was found to be higher $(10-17 \%)$ compared to the present study. However, the results in the present study are comparable with the work of Leitao et al. [13] on the dissimilar friction stir welding of AA5182 and AA6016, in which the \% elongation was obtained as $8 \%$, and the UTS and YS were $200-220 \mathrm{MPa}$ and 115-150 MPa, respectively.

\section{Conclusions}

(1) Friction stir welding of dissimilar materials AA5052 and AA6061 was successfully performed. It was observed that at higher rotation speeds, the normal load and spindle torque requirement decreased.

(2) The microstructural studies suggested that there was no rigorous mixing of both materials in the nugget. There was an abrupt change in the microhardness 


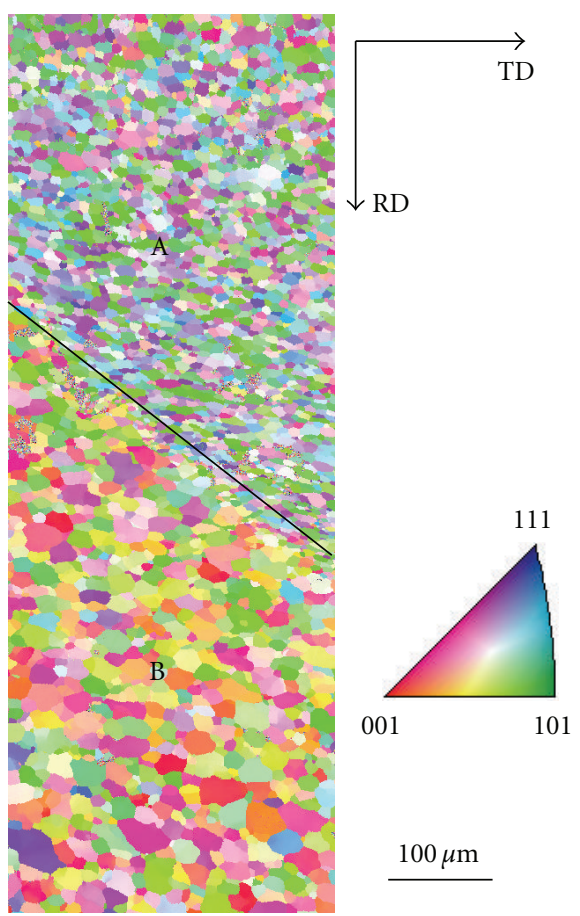

(a)

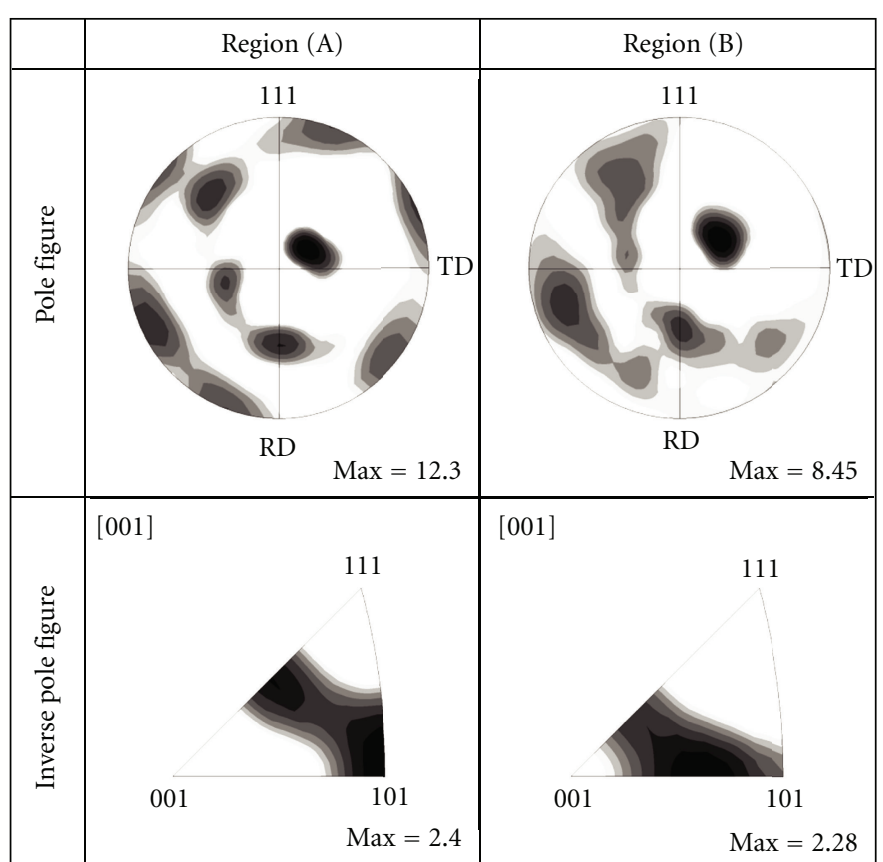

(b)

FIgURE 4: (a) Inverse pole figure map of the region across the interface of AA5052 and AA6061 in the nugget of FSW AA5052-AA6061 specimen. (b) Chart showing the pole figure and inverse pole figures for the various regions marked in (a).

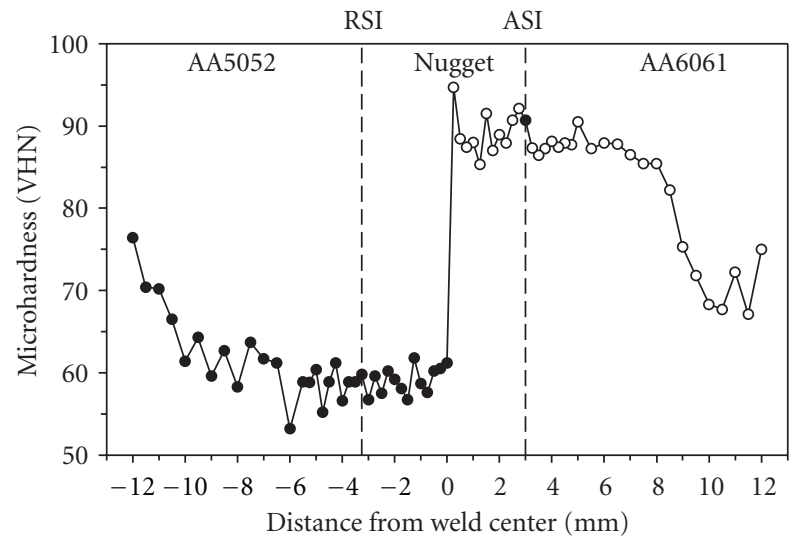

FIGURE 5: Microindentation hardness distribution across the transverse cross-section of FSW AA5052-AA6061 R1400F080 specimen.

across the interface in the nugget. However, electron probe microanalysis results stated that there was bonding at the atomic scale due to substantial interdiffusion of alloying elements at the interface of both the alloys in the nugget. Further, orientation imaging microscopy at the interfacial region suggested that despite the nonrigorous mixing and materials holding on to their domain, both the materials exhibited similar texture.

(3) Thus the interdiffusion of alloying elements and attaining of similar orientations in the nugget could

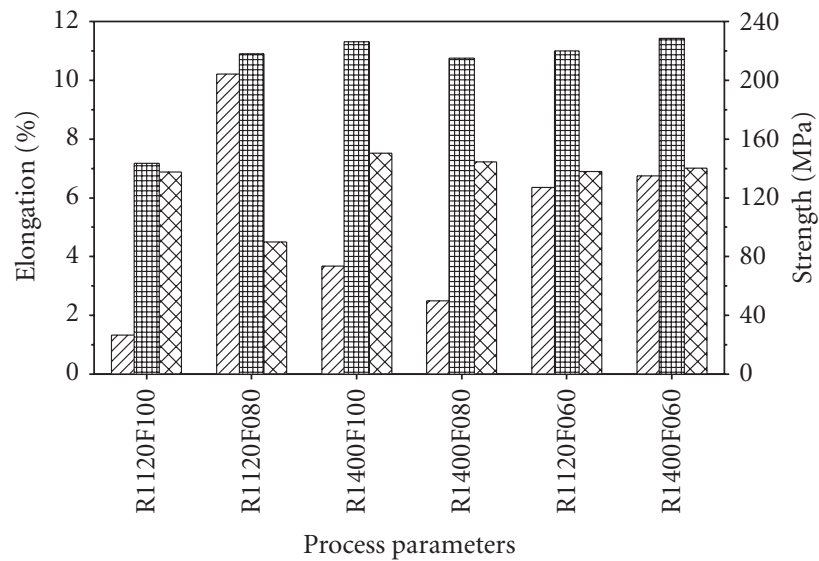

एws Elongation

UTS

$\mathrm{EXX}$ YS

FIGURE 6: The \% elongation, ultimate tensile strength (UTS), and yield strength (YS) for various combinations of process parameters for friction-stir-welded AA5052-AA6061 specimens.

have contributed to the good mechanical properties of the friction stir welded AA5052-AA6061 specimens. The tensile properties of the FSW AA5052AA6061 specimens were better than the properties of the softest of the similar friction-stir-welded systems (i.e., FSW AA6061). 


\section{Acknowledgments}

The authors would like to acknowledge Professor S. V. Kailas, Deptartment of Mechanical Engineering, Indian Institute of Science, Bangalore, for extending his support to carry out the friction stir welding experiments. The authors acknowledge the National Facility of Texture and OIM (a DST-IRPHA) facility for undertaking the microtexture studies. The first author acknowledges the fellowship provided by the Department of Atomic Energy, India, under the Mumbai University-BARC collaborative research scheme. The authors like to thank Dr. A. K. Suri, Director, Materials Group, BARC, and Dr. G. K. Dey, Head, Materials Science Division, BARC, for their keen interest in this work.

\section{References}

[1] C. Y. Lee, W. B. Lee, J. W. Kim, D. H. Choi, Y. M. Yeon, and S. B. Jung, "Lap joint properties of FSWed dissimilar formed $5052 \mathrm{Al}$ and $6061 \mathrm{Al}$ alloys with different thickness," Journal of Materials Science, vol. 43, no. 9, pp. 3296-3304, 2008.

[2] J. C. Park and S. J. Kim, "The effect of traveling and rotation speeds on mechanical properties during friction stir welding of dissimilar Al alloys," Defect and Diffusion Forum, vol. 297301, pp. 590-595, 2010.

[3] S. K. Park, S. T. Hong, J. H. Park, K. Y. Park, Y. J. Kwon, and H. J. Son, "Effect of material locations on properties of friction stir welding joints of dissimilar aluminium alloys," Science and Technology of Welding and Joining, vol. 15, no. 4, pp. 331-336, 2010.

[4] N. T. Kumbhar, S. K. Sahoo, I. Samajdar, G. K. Dey, and K. Bhanumurthy, "Microstructure and microtextural studies of friction stir welded aluminium alloy 5052," Materials and Design, vol. 32, no. 3, pp. 1657-1666, 2011.

[5] N. T. Kumbhar, Solid state methods for joining aluminium alloys, Ph.D. thesis, 2011.

[6] P. L. Threadgill, "Terminology in friction stir welding," Science and Technology of Welding and Joining, vol. 12, no. 4, pp. 357360, 2007.

[7] J. H. Ouyang and R. Kovacevic, "Material flow and microstructure in the friction stir butt welds of the same and dissimilar aluminum alloys," Journal of Materials Engineering and Performance, vol. 11, no. 1, pp. 51-63, 2002.

[8] P. Su, A. Gerlich, T. H. North, and G. J. Bendzsak, "Intermixing in dissimilar friction stir spot welds," Metallurgical and Materials Transactions A, vol. 38, no. 3, pp. 584-595, 2007.

[9] A. Gerlich, P. Su, M. Yamamoto, and T. H. North, "Material flow and intermixing during dissimilar friction stir welding," Science and Technology of Welding and Joining, vol. 13, no. 3, pp. 254-264, 2008.

[10] O. Lorrain, V. Favier, H. Zahrouni, and D. Lawrjaniec, "Understanding the material flow path of friction stir welding process using unthreaded tools," Journal of Materials Processing Technology, vol. 210, no. 4, pp. 603-609, 2010.

[11] J. C. McClure, Y. Li, R. Flores et al., "Intercalation vortices and related microstructural features in the friction-stir welding of dissimilar metals," Materials Research Innovations, vol. 2, no. 3, pp. 150-163, 1998.

[12] K. Colligan, "Material flow behavior during friction stir welding of aluminum," Welding Journal, vol. 78, no. 7, p. 229-s, 1999.
[13] C. Leitao, R. M. Leal, D. M. Rodrigues, A. Loureiro, and P. Vilaça, "Mechanical behaviour of similar and dissimilar AA5182-H111 and AA6016-T4 thin friction stir welds," Materials and Design, vol. 30, no. 1, pp. 101-108, 2009. 

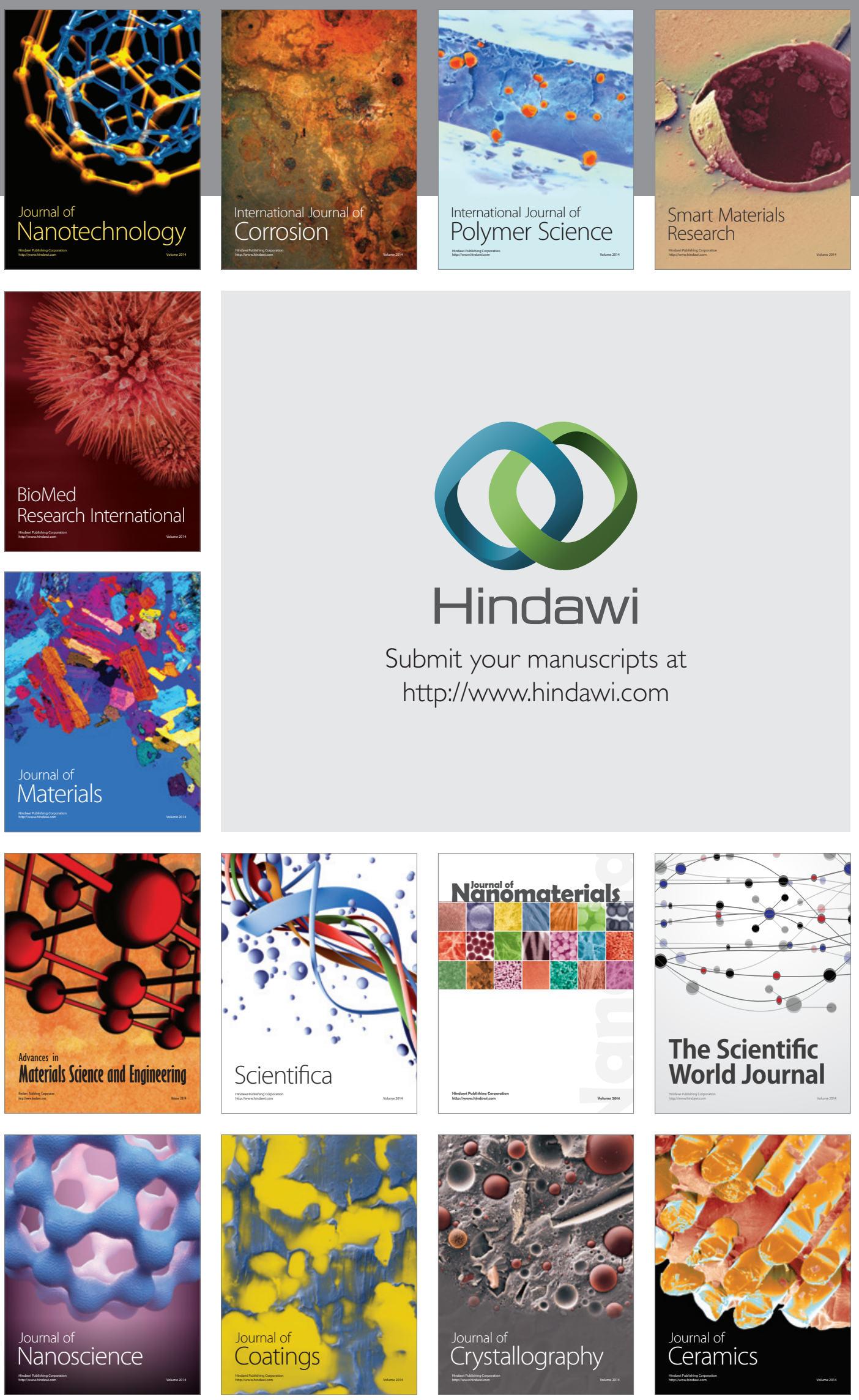

The Scientific World Journal

Submit your manuscripts at

http://www.hindawi.com

\section{World Journal}

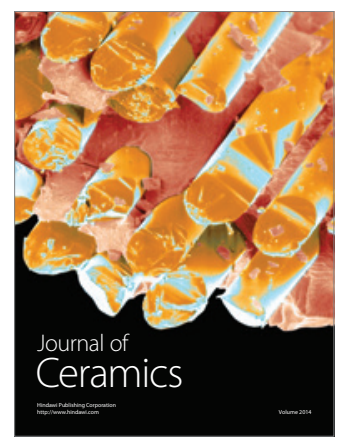

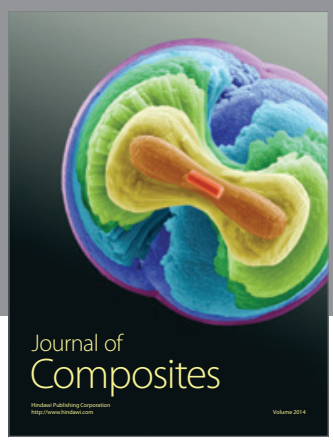
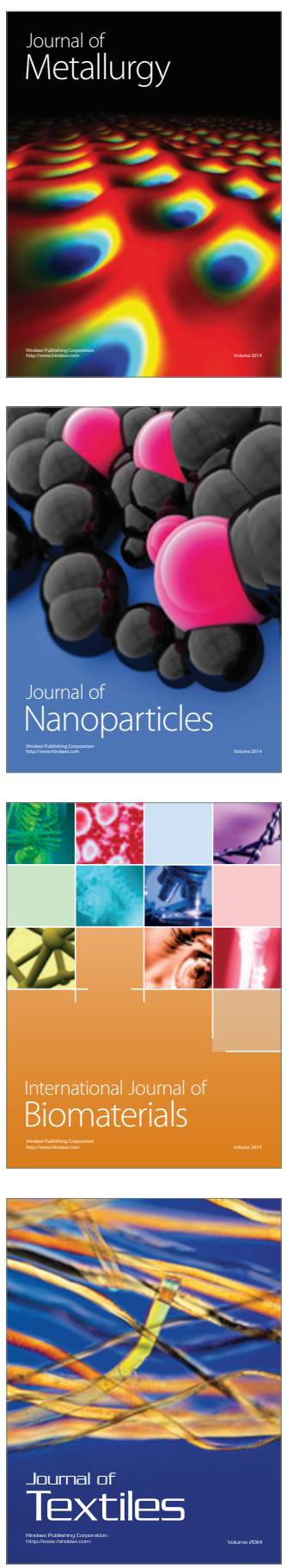